\title{
Gènere i política als mitjans nord-americans
}

CP 2014, Vol.3-N5, pp. 105-107. ISSN 2014-6752. Girona (Catalunya). DOMÈNECH MORRO, Sònia: Gènere i politica als mitjans nord-americans Recibido: 19/12/2014 - Aceptado: 22/12/2014

\section{Hillary Clinton in the News: Gender and Authenticity in American Politics}

\section{Shawn J PARRY-GILES.}

Urbana, Chicago and Springfield: University of Illinois Press, 2014.

258 páginas

ISBN: 978-0-252-07978-8

Ebook: 978-0-252-09604-4

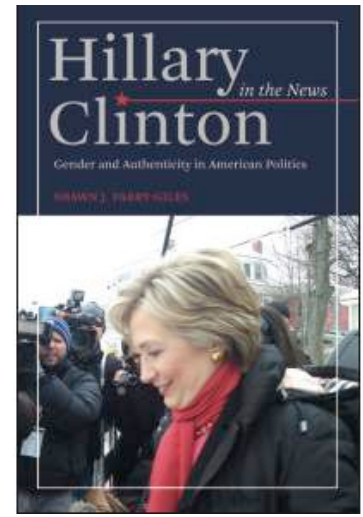

\section{Sònia DOMÈNECH MORRO}

Estudiant del Màster en Mitjans, Comunicació i Cultura de la Universitat Autònoma de Barcelona. sdmorro@gmail.com

Què passa quan una dona irromp en l'esfera política, històricament dominada per homes? Shawn J. Parry-Giles analitza de forma exhaustiva la reacció dels mitjans de comunicació davant de la presència de Hillary Rodham Clinton, des del seu paper a la campanya electoral del seu marit, Bill Clinton, l'any 1992, fins a la seva pròpia campanya per a les primàries del partit Demòcrata, l'any 2008 .

El llibre "Hillary Clinton in the News. Gender and Authenticity in American Politics" estudia com, a través del concepte d'authenticity, es legitima o no el caràcter i les capacitats d'un personatge públic. Aquest concepte es refereix al conjunt de valors que la societat nord-americana atorga als polítics, d'acord amb certes expectatives morals i ètiques. L'autora fa especial referència a l'impacte de les qüestions de gènere a l'hora de definir aquesta autenticitat en la representació mediàtica de Hillary Clinton. Per a realitzar aquesta anàlisi, Parry-Giles analitza el tipus de llenguatge que fan servir les principals cadenes de televisió nordamericanes, així com els judicis i valoracions que empren quan es refereixen a Clinton.

A través dels quatre capítols que conformen l'obra, Parry-Giles il·lustra com, en una societat patriarcal, el binomi home-dona genera una divisió de l'espai que es materialitza en un nou binomi, públic-privat, que tradicionalment ha exclòs les dones de la vida política, en tant que pública. Hillary Clinton va desafiar, ja a principis dels 90, aquesta premissa, situant-se al capdavant durant la campanya electoral de Bill Clinton.

Aquests fets van suposar, com mostra ParryGiles, una transgressió del paper tradicionalment atorgat a una primera dama, posant contra les cordes la vigència d'aquest, fet que va fer sonar les alarmes als mitjans nord-americans.

L'autora ens guia en un viatge a través de la cobertura mediàtica de la trajectòria política 
de Hillary Clinton. Inicialment, doncs, els mitjans la presenten com una inusual dona política, membre activa de la campanya del seu marit, amb capacitat de generar discurs propi. Els mitjans, segons Parry-Giles, utilitzen frames (enquadraments) per a construir, a través del llenguatge, un discurs que crea una imatge determinada sobre Clinton. En aquesta primera etapa es fa servir la idea d'ella com a feminista, com a dona progressista que es confronta amb els valors tradicionals de la dona americana. Per això s'utilitzen eines que van des de declaracions de la pròpia Hillary Clinton fent referència a una definició de si mateixa que difereix d'aquest model tradicional de dona, fins a conceptes creats pels mitjans com són el Hillary Factor, per referir-se a la seva particular idiosincràsia transgressiva, més pròpia d'un home, o la metàfora del lightning rod (parallamps), per a referir-se a ella com a centre del debat polític, qualificant-la de parlar massa, sense embuts. Una altra idea que és present en el discurs dels mitjans en aquesta primera fase és la de co-presidència, és a dir, el candidat no és només Bill, si guanya, governaran els Clinton.

En aquesta època, com descriu Shawn J. Parry-Giles, s'ofereix una imatge que situa a Clinton com una amenaça, un perill per a l'status quo masculí en el món de l'alta política. Tots aquests frames impregnen el discurs que acompanyarà Hillary Clinton al llarg de la seva carrera política.

L'autora observa com, un cop passada la campanya electoral, amb Hillary Clinton com a primera dama, els mitjans segueixen insistint en la contradicció existent entre la idea de la primera dama tradicional, discreta i entregada al seu marit i la seva pàtria, i la primera dama feminista, empoderada, que treballa al costat del president. Hillary Clinton és una peça clau en el govern del seu marit. En concret, lidera la reforma de la sanitat, una de les apostes polítiques més ambicioses de la legislatura. Parry-Giles descriu com, durant la campanya, els mitjans segueixen arrossegant les idees que han caracteritzat fins llavors la primera dama, amb discursos carregats de retòrica de guerra i mort que generen una imatge de violència, que s'arriba a materialitzar en forma de violència cap a ella; així com amb llenguatge sexualitzador, un recurs fàcil per parlar d'una dona en un espai exclusivament masculí.

El fracàs de la campanya de la sanitat, atribuït en part a la gestió de Hillary Clinton, sumat al Whitewater, un presumpte cas de corrupció que va esquitxar els Clinton quan Bill era governador d'Arkansas, van contribuir a la perpetuació del llenguatge disciplinador dels mitjans sobre la primera dama. Amb aquests precedents, Clinton va passar a ser emissària internacional dels Estats Units.

En la seva època com a emissària internacional té lloc el cas Lewinsky, una nova crisi a què ha de fer front Hillary Clinton que acaba amb la seva victimització com a esposa traïda. Això, afegit al fet que es troba fora del país, potencia un canvi d'enfocament en el discurs dels mitjans. Com bé mostra Shawn J. Parry-Giles, Clinton ja no és el centre d'atenció del debat polític, no es troba a la capçalera. Els mitjans es fan ressò d'una primera dama que es mobilitza pels drets humans, pels drets de les dones i els infants, situant-se en una esfera més adequada per la seva posició.

No obstant això, el fet que decideixi seguir amb el seu marit després de la infidelitat reforça dues idees. D’una banda, la idea que el seu matrimoni és una eina per a entrar en l'esfera política. De l'altra, que aquest gir en el seu caràcter respon a una estratègia política basada en un canvi d'imatge.

Totes les idees expressades pels mitjans al voltant de la figura de Hillary Clinton ressorgeixen quan, l'any 2000, decideix presentar-se com a candidata Demòcrata al Senat de Nova York. Aquesta notícia provoca reaccions diverses als mitjans. En general es produeix una sexualització de la seva figura a través del discurs. De nou, es qüestiona la seva autenticitat com a candidata, al·ludint als avantatges del seu contrincant Republicà i qualificant-la d'oportunista, d'utilitzar les eleccions al Senat com a un graó més en la seva carrera política que vol culminar amb les eleccions presidencials. En aquest moment sorgeixen nous frames que serveixen per descriure Hillary Clinton, aquest cop fent 
referència a l'oportunisme (carpetbagger), a la seva inexperiència política i a la seva condició de celebrity.

En aquest cas i al llarg de tota la trajectòria pública de Hillary Clinton, els mitjans la defineixen a través d'una "retòrica agresiva d'esports, guerra i violència, és enquadrada especialment con una dona feminista" (ParryGiles, 2014: 161). Una retòrica que es cristal-litza amb les metàfores de la lluita política per guanyar les eleccions, la referència a Clinton com a dona maltractada i victimitzada pel cas Lewinsky i, fins i tot, actuacions invasives del propi espai per part del seu contrincant al Senat de Nova York. Aquest llenguatge de violència, a més, serveix com a amenaça per a les dones que vulguin posar els peus a l'arena política. Tots aquests recursos es reprodueixen en la campanya de Hillary Clinton per a les primàries del partit Demòcrata l'any 2008, quan es parla directament de la necessitat de "portar-la darrere del graner [take her behind the barn]” (Parry-Giles, 2014: 171), una expressió amb clares connotacions sexistes.

Shawn J. Parry-Giles posa de manifest com els mitjans de comunicació construeixen la realitat a través del llenguatge: "la narrativa de les notícies combinada amb altres discursos politics contribueix al imaginari nacional” (Parry-Giles, 2014: 177). Així, els mitjans exerceixen de mediadors entre el públic i els polítics, actuant com a biògrafs i jutges de la seva autenticitat (Parry-Giles, 2014: 178). Els missatges que transmeten ajuden a construir referències concretes en l'imaginari i, fins i tot, poden arribar a modificar la realitat a la qual es refereixen. D'això n'és exemple el fet que Hillary Clinton modifiqués la seva actitud com a figura pública després de la crisi de la reforma de la sanitat i l'escàndol del Whitewater. Tot i això, altres exemples demostren que aquesta capacitat dels mitjans també té límits, ja que, tot i les crítiques constants a l'autenticitat de Hillary Clinton, va resultar guanyadora al Senat de Nova York.

D’altra banda, el llibre de Parry-Giles posa de manifest els valors sexistes profundament arrelats a la societat nord-americana, que es materialitzen en forma d'un constant atac a la capacitat d'una persona per a transcendir de l'espai privat a l'espai públic pel simple fet de ser dona. Veiem, doncs, com els mitjans tenen un paper fonamental a l'hora d'estructurar una representació determinada de les dones. La situació d'alarma que reprodueixen quan una dona transgredeix el seu rol de gènere evidencia que l'empoderament de les dones representa una situació incòmoda per a aquells que historicament han ostentat el poder. Com afirma la pròpia autora, tot això posa de relleu "tot el que queda per davant abans de que una dona pugui entrar en política sense haver-hi de fer front a amenaces per actuar fora dels limits d'una nació centrada en el gènere de les persones" (Parry-Giles, 2014: 197).

\section{Forma de citación}

DOMĖNECH MORRO, Sònia: Gènere i política als mitjans nord-americans. Revista Communication Papers, No5, páginas 105 a 107. Departamento de Filología y Comunicación de la Universidad de Girona. Recuperado el _ de de 2 de: http://www.communicationpapers.es 